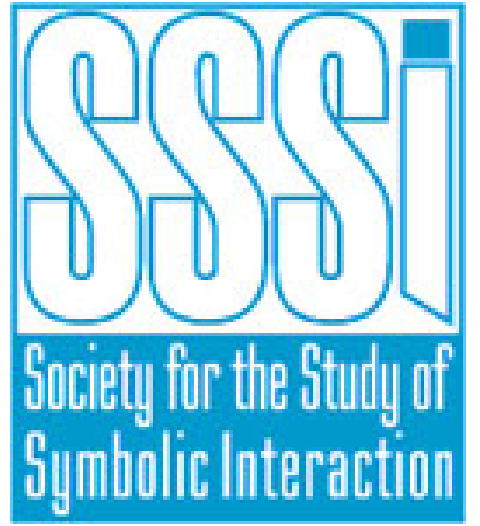

Narrating Nursing Jurisdiction: "Atrocity Stories" and "Boundary-Work" Author(s): Davina Allen

Source: Symbolic Interaction, Vol. 24, No. 1 (2001), pp. 75-103

Published by: University of California Press on behalf of the Society for the Study of Symbolic Interaction Stable URL: http://www.jstor.org/stable/10.1525/si.2001.24.1.75

Accessed: $12 / 09 / 201104: 57$

Your use of the JSTOR archive indicates your acceptance of the Terms \& Conditions of Use, available at http://www.jstor.org/page/info/about/policies/terms.jsp

JSTOR is a not-for-profit service that helps scholars, researchers, and students discover, use, and build upon a wide range of content in a trusted digital archive. We use information technology and tools to increase productivity and facilitate new forms of scholarship. For more information about JSTOR, please contact support@jstor.org. 


\title{
Narrating Nursing Jurisdiction: "Atrocity Stories" and "Boundary-Work"
}

\author{
Davina Allen \\ University of Wales College of Medicine
}

\begin{abstract}
Sociologists have long recognized that the division of labor is, at its root, a process of social interaction. Although "negotiations" figure centrally in symbolic interactionist studies of work, relatively little attention has been given to the ways in which the structure of workplace talk contributes to the social constitution of occupations. Drawing on the insights of discourse and conversation analysis, this article examines occupational atrocity stories and considers how they accomplish boundary-work in the hospital setting. I focus on the stories British nurses told about doctors and use data generated in ethnographic research into the routine accomplishment of nursing jurisdiction. I conclude with some general observations about how the detailed analysis of stories and storytelling can contribute to the wider study of social group formation.
\end{abstract}

Symbolic interactionists have long recognized that the division of labor is, at its root, a process of social interaction (Abbott 1988; Freidson 1976; Hughes [1971] 1984; Strauss et al. 1963; Strauss et al. 1985). However, relatively little attention has been given to how the structure of workplace talk contributes to the social production of occupational boundaries. For example, because of their complex division(s) of labor, hospital settings are of particular interest to students of the sociology of work and occupations. Possibly gaining its impetus from Strauss and his colleagues' negotiated order perspective, over the past thirty years we have witnessed a raft of symbolic interactionist research on hospital work. Despite the centrality of "negotiations" to interactionist theoretical foundations, few of these studies have focused on the detail of talk in social interaction (Mellinger 1994) and its relationship to the division of labor. Rather, these analyses have either centered on symbolic signifiers of occupational difference (Atkinson 1981; Haas and Shaffir 1987) or what actors' talk reveals of broader work cultures (Anspach

Direct all correspondence to Davina Allen, Centre for Nursing, Health and Social Care Research, School of Nursing and Midwifery Studies, University of Wales College of Medicine, Health Park, Cardiff CF14 4XN, UK; e-mail: AllenDA@cf.ac.uk.

Symbolic Interaction, Volume 24, Number 1, pages 75-103, ISSN 0195-6086.

(c) $\mathbf{2 0 0 1}$ by the Society for the Study of Symbolic Interaction. All rights reserved.

Send requests for permission to reprint to: Rights and Permissions, University of California Press, Journals Division, 2000 Center St., Ste. 303, Berkeley, CA 94704-1223. 
1987, 1993; Bosk 1979; Chambliss 1997; Hughes 1988). As a consequence, in studies of work in hospital settings interactionists have neglected to study the micropolitical business that talk does in the interactional production of occupational boundaries. One possible reason for this analytic lacuna may be the difficulty that sociologists have experienced in obtaining data of this kind. It is only relatively recently that small portable tape recorders have become available to ethnographers, and, even where they are available, practical and ethical constraints may limit their use. Social scientists have provided many fine-grained analyses of talk in the professional-patient consultation (see, e.g., Hak 1994; Hughes 1982), but few studies focus on the interactional work talk does in the ebb and flow of routine hospital life. I aim to address this gap in the literature by examining one element of hospital talk and its role in the social production of occupational boundaries: the "atrocity" story (Dingwall 1977). As part of a narrative genre that figures prominently in interactionist studies of health care settings, these stories are about dramatic or shocking events that may take on a legendary or apocryphal status in the oral culture of an occupational group (Atkinson 1992; Bosk 1979). Although atrocity stories are often discussed in relation to the health care division of labor, little attention has been given to the micropolitical work that they do. By using ethnographic data from my doctoral research about the practical accomplishment of nursing jurisdiction in the United Kingdom (Allen 1996), I focus on the atrocity stories told by hospital nurses, particularly their tales about doctors. Discourse and conversation analytic insights are used to reveal the ways in which both the rhetorical form of nurses' tales and their storytelling practices function to create a moral boundary between nurses and medical staff.

There has been much debate in recent years about the desirability of combining ethnography with conversation and discourse analysis (Moerman 1988; Nelson 1994; Spencer 1993; West 1996). Support for such a synthesis appears to be driven by both analytic and practical concerns. Some scholars take the view that ethnographic data may enhance the analysis of transcribed talk (see, e.g., Moerman 1988). Others adopt a more practical stance. Recognizing that the tape recording of social interaction of all kinds is not always possible, a number of analysts have argued that theoretically informed observers can produce real-time field notes that may be fruitfully analyzed from a conversation analytic standpoint (see, e.g., Atkinson and Drew 1979; Holstein 1993; Miller 1997). Reservations have been expressed about such a marriage. Some researchers argue for the distinctive focus of conversation analysis on the organization of talk-in-interaction as a topic in its own right (Heritage 1990-91, cited by West 1996; Hopper 1990-91, cited in Nelson 1994; Maynard 1989, cited by Miller 1997; Potter pers. com. 1998) while others have pointed to the limitations of field note transcripts compared to tape recordings (West 1996). Notwithstanding these considerations, I take the view that discourse and conversation analytic insights can make a valuable contribution to traditional ethnographic work. 


\section{NARRATING SOCIAL BOUNDARIES}

\section{Stories and Storytelling}

Stories and storytelling are a central feature of all social life. They are "ways of packaging experiences" (Sacks 1978:259) and the standard form for communicating them (Ehlich 1980, cited in Davis 1988). Remarking on the ubiquity of stories, Plummer (1995) goes so far as to suggest that we are Homo Narrans: humankind the narrator. He argues that we may consider society a web of stories that emerge through interaction. Stories hold people together and pull them apart; hence they are part of the micropolitical processes that make society work.

Stories occupy a special place in the culture of health and illness. They are the medium through which patients talk to sociologists (Brock and Kleiber 1994; Davis 1988, 1995; Kleinman 1988; Williams 1984) and package their illness "experiences" in medical encounters (Clark and Mishler 1992; Davis 1995). Medical practice is predicated on the regular round of storytelling about patients (Hunter 1991). The public presentation of a case provides an important mechanism through which medical staff demonstrate their competence (Atkinson 1995; Bosk 1979). Staff also use stories to negotiate patient "deservingness" in rationing scarce resources (Griffiths and Hughes 1994).

\section{Atrocity Stories}

It is in discussions of the "atrocity" or "horror" story that the analytic links between occupational boundaries and storytelling are made most explicit (Bosk 1979; Dingwall 1977; Finlay et al. 1990; Turner 1986). Atrocity stories have been analyzed as (1) moral parables that remind doctors that medicine is a serious business (Bosk 1979); (2) vehicles for the transmission of an occupational culture (Atkinson 1992; Dingwall 1977; Turner 1986); (3) mechanisms for communicating shared difficulties (Bosk 1979; Dingwall 1977; Finlay et al. 1990; Turner 1986); (4) facilitators of occupational rites of passage (Hafferty 1988; Myers 1979); (5) resolvers of ambiguities over occupational frontiers (Dingwall 1977); (6) communicators of guilt (Bosk 1979); and (7) relievers of anxiety and tension (Bosk 1979; Dingwall 1977). What emerges from the literature is a picture of atrocity stories serving diverse social purposes, which often touch on occupational boundaries, although researchers have not always made this association explicit.

The most sustained examination of the relationship between atrocity stories and occupational boundaries is Dingwall's (1977) work on United Kingdom health visitors. Dingwall argues that the stories health visitors told about general practitioners, social workers, and nurses played an important role in managing uncertainty about professional boundaries and helped to define the colleague group. According to Dingwall, staff acquire a repertoire of stories and should be able to identify appropriate occasions for telling them in order to become competent members of their respective occupations. 
This article builds on Dingwall's work but is different in two important respects. Although Dingwall explores the different social actions for which stories can be used-for example, he distinguishes between stories that serve to bind a group together and those that are employed to assert the reasonableness of an individualhe is not concerned with how they actually accomplish the purposes that he claims for them. ${ }^{1}$ To illustrate, he argues that storytelling contributes to social cohesion through the mutual affirmation of common problems, yet he does not demonstrate how stories constitute events as mutually troublesome. Similarly, he argues that staff use stories to transform insiders into outsiders but does not show us exactly how they achieve this function. To address such issues, I adopt a different style of analysis that pays closer attention to the rhetorical and interactional detail of the stories nurses tell.

Studying the fine grain of nurses' atrocity stories and the ways in which they tell and receive them highlights the micropolitical purposes they serve. That is, although at one level professionals can employ stories to accomplish a range of interactional business in the immediate social context, such as to illustrate a general observation, at another level stories may also be "oriented to "extra-situational agendas and concerns' [which are] accomplished through ... endogenously developing sequences of action" (Zimmerman 1998:88). In other words, stories may be affiliative or disaffiliative; they are an important means of constructing relationships and positioning people in relation to one another.

This orientation to extrasituational agendas and concerns is the second way in which my analysis differs from Dingwall's. Although Dingwall connects the stories health visitors told with their "professional project" (Larson 1977), he treats them primarily as a remedial device. He presents atrocity stories as a way of handling conflict when its overt expression is constrained (Stimson and Webb 1975; Webb and Stimson 1976). As Baruch (1981) observes, however, a difficulty arises with analyzing atrocity stories in this way; one has to invoke a psychological variable, when, as researchers, we do not have direct access to respondents' subjective experiences (Baruch 1981). ${ }^{2}$ I do not deny the significance of stories as a marker of social friction or their role in the management of occupational strains (particularly where there is an imbalance of power). But I aim to concentrate on the interactional work that atrocity stories demonstrably do. Accordingly, I treat nurses' atrocity stories as a form of boundary-work (Gieryn 1983,1999).

\section{BOUNDARY-WORK}

The concept of boundary-work was introduced by Gieryn $(1983,1999)$ to refer to an ideological style found in scientists' attempts to create a public image for the discipline by attributing selected characteristics to it that contrast it with nonscientific or technical activities. Gieryn (1983) focuses on the rhetorical form of scientists' boundary-work and the cultural space it creates for the discipline within the "intellectual ecosystem." Scientists have access to considerable material and professional 
opportunities that are not available to nonscientists, and thus scientists perform boundary-work as a highly political process in the pursuit of professional goals. As a consequence, science is no single thing; rather its boundaries are episodic and locally situated, rhetorically constructed and reconstructed according to the purposes at hand and the issues at stake.

Gieryn's substantive focus is on "public science," that is, the kinds of jurisdictional claims that scientists make for their disciplines in public and political settings. Moreover, he concentrates on specific "credibility contests" rather than the routine ways in which scientists rhetorically produce the boundaries of their disciplines in everyday practice. As Abbott (1988) has observed, however, jurisdictions are claimed in other kinds of arenas, by different segments of the occupation, and the context in which this occurs can critically shape how this is accomplished. For example, the precision with which jurisdictions are claimed in public and legal settings contrasts sharply with the reality of the workplace where formal lines of demarcation frequently break down. Gieryn (1999) argues that in the workplace explicit boundary contests are rare because occupational boundaries are based mainly on custom. Hence boundary-work does not figure very prominently in this domain. Moreover, when the site of work concerns matters of life and death, overt contests are likely to be particularly constrained.

Yet as sociologists from Durkheim (1933) onward have recognized, the division of labor has a moral as well as a technical dimension. Work has meaning for those who do it, and, as Hughes ([1971] 1984) observes, a role division of labor is necessary to complement any technical description of it. Shop floor members face the problem of reconciling the jurisdictional claims that are made for their occupation in the public domain with the daily reality of the workplace. How does one establish an occupational (moral) identity when the technical lines of demarcation routinely break down?

This kind of mundane identity politics is not featured in Gieryn's work, and I suggest it is at this level that atrocity stories assume their significance as boundary markers. They may perform boundary-work of a rather different kind from that which Gieryn describes, but atrocity stories are an important mechanism through which occupational difference is interactionally accomplished in the workplace. They are part of the political process by which bounded occupations are socially constituted. They are a way of talking jurisdiction. They do "identity work" (Hunt and Benford 1994; Snow and Anderson 1987).

\section{POLICY CONTEXT}

The data for this study were collected in the mid-1990s, at a point when developments in nursing and medical education (Department of Health \& Social Security 1987; General Medical Council 1993; United Kingdom Central Council 1987) and health policy (Department of Health 1989) in the United Kingdom had provided the impetus for realignment of the division of labor among nursing, medical, and 
support staff. Project 2000, the United Kingdom Central Council's (UKCC) wideranging reform of nursing education, structure, and practice (UKCC 1987), ${ }^{3}$ entailed (1) the relocation of nurse education from hospital-based schools of nursing to higher education institutes; (2) the establishment of a single portal of entry by abolishing the enrolled (EN) grade of nurse; ${ }^{4}(3)$ the reduction of learners' contribution to service provision from 60 to 20 percent, ${ }^{5}$ (4) joint professional and academic validation of training courses, which led to a diploma in higher education; and (5) a shift in the nursing curriculum from an emphasis on disease to an emphasis on health.

Project 2000 was an explicit professionalizing strategy, aimed to differentiate nursing from medicine and establish an autonomous practice domain. Predicated on a "New Nursing" (Salvage 1988) ideology, the reforms proposed a vision of nursing centered on a view of the relationship between practitioner and patient as unique. Project 2000 rejected the traditional skills hierarchy that accorded higher status to medically derived tasks than to bedside tending. It advocated the reintegration of caring work into the core nursing role rather than delegate it to unqualified staff as had occurred in the past.

At about the same time, concern with cost containment in the National Health Service (NHS) gained momentum. This period witnessed a number of policy developments that entailed the progressive introduction of "managerialism" into health care. Beginning with the publication of the Griffiths Report (Department of Health \& Social Security 1983) and consolidated in the 1990 NHS and Community Care Act, this "management revolution" (Klein 1995) was part of a systematic attempt to refashion the relationship between public sector professionals and the state by exercising greater control over their practice and use of resources.

Given this backdrop, the government's acceptance of the Project 2000 reforms seemed anomalous. As Rafferty $(1992,1996)$ has noted, however, the success of nurse-driven policy changes can be traced historically to their resonance with wider policy concerns, and in Project 2000 the government saw the opportunity to make savings by increasing efficiency. Acceptance of the proposals entailed an important condition: nursing leadership had to agree to the introduction of a new category of support worker, the health care assistant (HCA).

Despite nurses' aspirations for exclusive jurisdiction, untrained auxiliaries have always performed much of the hands-on care work. ${ }^{6} \mathrm{HCAs}$ would be trained for an even wider role, however, which would also embrace certain "technical" tasks such as the removal of intravenous catheters and the observation and recording of temperature, pulse, and blood pressure. Moreover, unlike auxiliaries who acquired their skills on the job, HCA training would be provided by the National Council for Vocational Qualifications, a generic_non-nursing — accrediting body responsible for a wide range of work-based vocational and technical education.

Project 2000 reforms aimed to differentiate clearly between qualified and unqualified staff, but the introduction of National Vocational Qualifications (NVQs) could well have precisely the opposite effect (Dingwall, Rafferty, and Webster 
1988) by making alternative qualifications available at the level of, and in competition with, professional qualifications (Shaw 1993). Moreover, these developments clearly conflicted with the aspirations of the proponents of New Nursing who wished to reclaim hands-on care as the rightful jurisdiction of qualified nurses.

A further key development, the "Junior Doctors' Hours Initiative" (National Health Service Management Executive 1991), aimed to improve the working conditions of trainee medical staff. To this end, an increased number of career-grade posts were recommended, as well as new ways of organizing junior doctors' work. Another element of the strategy suggested that certain clinical tasks be "shared" by nurses and midwives.

An additional impetus to the blurring of medical and nursing roles came from the publication of new guidelines on nursing role development by the UKCC: The Scope of Professional Practice (UKCC 1992). In the past nurses had to obtain "extended role" certificates, endorsed by doctors, to undertake work that was not covered by their basic training. The new framework overturned the hierarchical relations implicit in this system and shifted the onus for defining the scope of nursing practice to individual practitioners themselves.

The combined effect of these developments created considerable uncertainty as to the legitimate limits of the nursing role. Debates about the future shape of nursing work reverberated throughout professional and policy circles, echoing longstanding historical tensions between "professional" and "service" versions of nursing. Nurses expressed mixed responses. Some nurses supported a vision of nursing based on "care," whereas others maintained that the route to occupational progress was through the absorption of "medical" activities. For example, Yvonne Moores, the UK chief nursing officer, wrote in support of nurses undertaking doctordevolved work in the Nursing Times. She claimed:

The Scope of Professional Practice marks a major step forward. ... [T] hese principles should enable nurses ... to demolish artificial and unhelpful barriers to their practice.... [T] hey begin a process which affords all practitioners the opportunity to develop and use their education, skills and knowledge to maximize their contribution to patient care and at the same time achieve the highest level of personal fulfillment. (Moores 1992:28-29)

Others took a less sanguine view and expressed concern that by absorbing doctors' work nurses would lose sight of their primary caring function.

Nurses may have come to believe that "real" nursing is that which is associated with acute, scientific medical intervention. It needs to be made clear that the pursuit of the technical "instrumental" act has no purpose if it is not built on a sound understanding of the nature of nursing, combined with the "softer" skills of caring. (Wright 1995:27)

As we have seen, at that time management ideologies had gained momentum in health care. The strain toward dilution and the delegation of hands-on care work to support staff was indeed strong. Can nurses embrace new task areas, and, if so, will 
this lead to the loss of their caring functions? Is it possible to combine the two? Drawing on interactionist theories of the division of labor (Abbott 1988; Freidson 1976; Hughes [1971] 1984; Strauss et al. 1963; Strauss et al. 1985), my aim is to explore how nurses at the point of service delivery managed these tensions and negotiated their occupational boundaries in the course of their everyday work activities.

\section{THE RESEARCH}

The research was undertaken at Woodlands, ${ }^{7}$ a 900 -bed district general hospital in the middle of England, ${ }^{8}$ where a number of developments were being implemented that had implications for the scope of nursing practice. For example, efforts were being made to expand nurses' occupational boundaries by incorporating elements of junior doctors' work and to introduce a new HCA role.

Consistent with the debates in the national arena, nurses at all levels of the organization expressed ambivalence about the changes taking place. But while the thrust of national policies had created boundary disputes and some energetic efforts to shore up occupational frontiers in the management arena (Allen 2000, 2001), at the ward level shifts in role boundaries were being accomplished with minimal negotiative effort ${ }^{9}$ and little evidence of overt conflict (Allen 1997, 1998; Allen and Lyne 1997). In fact, the practical concerns of caring for patients in a turbulent environment resulted in staff routinely crossing occupational boundaries well beyond the limits of the formal role realignment taking place in the study site (Allen 1997; Allen and Lyne 1997). Apart from the usual signifiers of occupational difference found in hospital settings - such as uniforms and other insignia - telling atrocity stories was the principal mechanism through which ward nurses established a sense of occupational difference and constituted nursing as a bounded occupation.

\section{THE DATA}

Data were generated over a ten-month period through fieldwork that I conducted on a medical ward and a surgical ward (three months on each). Although I am a nurse and I stated my occupational background clearly, I was not employed as such during the fieldwork. My research role ranged from observer to participant, depending on the exigencies of the field. Sometimes I positioned myself at the nurses' station from where I could observe the unfolding "work drama" (Hughes [1971] 1984). On other occasions I adopted a more participative role. I assisted with bed making, served meals, fetched patients fresh water, and passed on telephone messages. Indeed, when the ward was busy it was actually very difficult to resist the urge to pitch in. At the same time, however, I also knew of the dangers of overstepping the mark and being perceived as interfering.

I gathered additional ethnographic material about the broader organizational context through attendance at management-level meetings and a range of in-service training days. In these situations I endeavored to maintain the stance of a detached 
observer, although occasionally staff invited me to participate. I was able to tape record most of these events but wrote observational notes when permission to tape record was denied.

I conducted fifty-seven tape-recorded, semifocused interviews with ward nurses $(n=29)$, doctors $(n=8)$, auxiliaries $(n=5)$, health care assistants $(n=3)$ and clinical managers $(n=11),{ }^{10}$ each lasting between an hour and an hour and a half. At less busy times, I also engaged in extended conversations with staff that were not tape recorded but were more detailed and reflective than the briefer discussions held with field actors while they worked. Organizational documents, such as meeting papers and training materials, also provided data sources.

I did not begin the research with a special interest in stories. Instead, I wanted to study how nurses negotiated their work boundaries in daily practice. Nevertheless, the formative power of talk always concerned me. As Heritage (1984) has pointed out, at its most fundamental level social reality is "talked into being." Accordingly, I used tape recordings when practical and otherwise made behaviorist field notes. Thus, rather than rely on my glossed interpretation of events, I obtained nearverbatim transcripts. Clearly, some environments are more transcription-friendly than others, and even verbatim field notes omit much of the detail of talk-in-interaction that is of interest to conversation and discourse analysts (West 1996). However, for those interested in more traditional ethnographic concerns, rigorous attention to the detail of talk permits a level of analysis not possible to achieve with field notes of a more broadly descriptive style. Still, this approach may not match the rigor associated with "pure" discourse and conversation analytic work.

Talk figured centrally in my original study, but the time frame did not permit its detailed analysis. Although I considered the boundary-work role of nurses' atrocity stories in my doctoral thesis (Allen 1996), I did not attend to their microsociological detail, or the ways in which they were interactionally produced. In short, like many other hospital studies of its kind, I did not show how nurses' stories achieved the interactional work that I claimed for them. For current purposes, it has been necessary to retranscribe some of the tape-recorded material to capture the richness of the interactional detail and to permit a finer-grained analysis than was possible within the time frame of the original study. In these instances I have employed simplified transcription notation, derived from those developed by Jefferson (1984, reproduced in Heritage 1984).

\section{THE STORIES}

Nurses produced atrocity stories in a variety of contexts and used them for a number of interactional purposes. Many emerged naturally and were threaded through the warp and weft of everyday work. Nurses told stories during the intershift handover or when taking coffee in the canteen. Stories also arose in meetings and during in-service training days. Nurses also produced a number of stories for my benefit, either in the context of conversations held with me while they worked or in 
the interview situation. I also told stories of my own to establish rapport with the research participants and present myself as someone who knew "how things really were."

Nurses told stories of many kinds, but doctors figured in them more prominently than any other occupational group. Given the relationship between the occupations of nursing and medicine and the significance of atrocity stories as markers of social friction, these findings are not surprising. Despite their desire for a clearly defined area of autonomous professional expertise, in practice nursing's "care" functions and the biomedical concerns of medicine overlap considerably. Furthermore, nurses remain subordinate players in the hospital division of labor, although they may aspire to parity of esteem with doctors. This situation clearly creates tensions and strains. The social organization of hospital work forces nurses to work with a shifting population of doctors in training who frequently know less about the clinical specialty than they do. Despite being uniquely placed to assess the caliber of junior medical staff, nurses have no formal control over their practice; instead this control rests with the consultant, who only attends the ward episodically.

At one level nurses' atrocity stories expressed the tensions they experienced in their working relationships with junior doctors. At another level they also did micropolitical work. Nearly all the stories nurses told about doctors were negative in some way. For example, nurses criticized their interpersonal skills, clinical competence, and disregard for appropriate procedures and protocols. I have only one example in my data corpus in which a doctor is presented favorably. In this deviant case, a UK doctor's competence is contrasted with the (in)competence of his overseas colleague. Moreover, although nurses assembled their stories to do different kinds of interactional work in the immediate context in which they were told, they employed a common discursive repertoire that constituted the nurse-medical boundary in remarkably consistent ways.

\section{Atrocity Stories - A Dual Boundary-Work Function}

Unlike Gieryn's $(1983,1999)$ scientists, who directed their boundary-work at a public audience, nurses recounted stories primarily for other members of the nursing group. HCAs were occasionally recipients of the stories nurses told, but nurses never produced these kinds of stories in front of doctors, or patients and their families. This shows one way in which the boundary-work that atrocity stories do in the workplace differs from that which takes place in the public domain. In addition to constructing social difference between the occupations of nursing and medicine rhetorically, the pattern of nurses' storytelling simultaneously constitutes membership of the nursing group.

Nurses' atrocity stories accomplish this dual boundary-work function in several interrelated ways: they employ contrastive rhetoric (Hargreaves 1981), which juxtaposes the medical and nursing perspective; they isolate the doctor and align the story recipient(s) with the nursing standpoint; and they constitute nurses' relation- 
ship with doctors as shared, thereby underlining their common occupational identity. This is accomplished through the discursive features of the stories and also in the way in which nurses interactionally produce and receive them.

\section{Constituting Insiders and Outsiders: The Boundary-Work of Atrocity Stories}

In the analysis that follows, I examine some examples of nurses' stories to reveal how they accomplish boundary-work. I begin with a detailed extract, produced in the interview context, to illustrate a number of the recurring features of the stories nurses told about doctors. The story is organized around the teller's circumstances and constructed from her standpoint; she assembles the tale to juxtapose medical and nursing perspectives and to achieve alignment with the nursing position. The story arises from a discussion about the relationships between doctors and nurses on the ward. The staff nurse (SN) has identified one doctor as unwilling to take advice from nurses. I ask whether she can recall any incidents to illustrate her point.

\section{Extract 1: Interview, Staff Nurse}

DA: So are there any particular incidents which have arisen where?

SN: Oh yeah this afternoon we've had one. 2

DA: Tell me! 3

SN: You know Mr Maple don't you in bed one. We'd all arranged for him to go 4 ho:me $=\quad 5$

DA: Mmm Hhh 6

SN: = and he was all ready, his family were brilliant erm, they'd got all this 7 back-up for him they were quite happy for him to go home with a 8 catheter ((tube which drains urine from the bladder)) in and then Angus 9 ((doctor)) did the round ((ward round)) and said "He's stopping (.) e::rm I 10 don't want him to go home with his catheter in. $\uparrow$ Take it out 11 (.) if he's okay over the weekend then he can go home" (.) 12 and we thought oh my god we've made all these arrangements (.) 13 so I said to Sister Lumley I said "He's not doing that" I said "I'm sorry" I 14 said "he's not doing that at all" (.) so I said "Will you have a word with 15 him" I says "because if I have a word with him I'll probably shout at 16 him and he'll probably just laugh" (.) So she says "Yeah okay I'll have a 17 word." So she told him she says "Look you know we've got a district 18 nurse going in (.) his family are happy to keep the catheter in because 19 he was incontinent at home (.) they couldn't go out anywhere because 20 he was always incontinent and they were just quite happy now they'll 21 be able to take him out and not have to worry and he won't worry 22 either" you know and he wouldn't have it "No, no I'm sorry I'm not happy 23 about it (.) he's stopping" when actually Dr Brown ((Consultant)) had 24 said he could go ho:me this weekend you know so then we told 25 Daphne ((named nurse $))^{11}$ and Daphne just got really upset (.) and she says 26 "That's it" she says "Now I'm going to have a go at ((confront)) him now," 27 she says "I don't care" so Daphne went and had a go at him and she says 28 "He ummed and arrhed and got a bit funny with her (.) got a bit shirty" 29 ((annoyed)) she says "but you know" she says "this man's been looking 30 forward to going home all day (.) his relatives have been so pleased to get 31 
him ome you know" (.) all Angus Prowse kept saying "Well he shouldn't

really go home with his catheter in im." He's got erm some sort of valve

disorder ((heart problem)) and this that and the other but we were saying

"Well you know (.) they know the man's condition (.) they know that

they'll probably not have long with him (.) they want to share all they ca $\uparrow \mathrm{n}$

This nurse constructs her story on the basis of an implicit comparison of the nursing and medical position. She employs contrastive rhetoric: portraying the doctor as having a narrow biological focus and juxtaposing this with the nursing perspective, which she represents as oriented to the psychosocial well-being of the patient and family. Within this overall framework, the story is designed so as to align the recipient with the nursing stance. A key feature of this data extract is that the viewpoint of the nurses, the patient, and the patient's family is presented in detail, but scant attention is given to that of the doctor.

The story begins at line 4 ("You know Mr. Maple") where the storyteller attempts to establish familiarity with the case. The scene is set in lines $4-5$ when the nurse describes how all the necessary provisions have been made for the patient to go home. She portrays his family as "brilliant"; they have gone to exceptional lengths to arrange for his homecoming. This detailed description of the extensive preparations made for the patient's discharge contrasts with the nurses' portrayal of the doctor, whose decision to postpone discharge is reported as a single terse announcement. She follows this point with an extended account of the nursing response in which the nurses' emotions figure prominently. The inclusion of emotional details orients the story recipient to what kind of story this is and whose side the narrative is on. Notice, also, the teller's use of "we" at lines 4, 13, 18, and 34. Although it is unclear whether the "we" refers only to nurses or to nurses and the patient and his family, taken as a whole, the narrator clearly sets up the story to isolate the doctor.

Another interesting segment in this extract is the account of the ward Sister's response to the doctor (18-25). Here the reasoning behind the nurses' perspective is described in some detail. But not only is the rationale for the doctor's position glossed over by the storyteller, she presents it as at odds with the consultant's opinion.

When the Sister's efforts of persuasion fail, Daphne, the nurse assigned to the patient, gets involved. Unlike the storyteller, she is prepared to jeopardize her relations with the doctor-who "got a bit shirty" - to protect the interests of her patient. Daphne's reported talk is interesting because it contains an explicit statement of the nurses' alignment with the family and their concerns. Family members know that it is risky to bring the patient home, but they recognize that he is dying, and they would rather spend time with him even if this means shortening his life. Daphne portrays the doctor, however, as removed from the world of real relation- 
ships. Moreover, with the production of the "significance aspect"12 (Ryave 1978) of the story at lines $38-39$, she also suggests that his actions derive from a preoccupation with status rather than the interests of his patients. Although this story points to how the medical-nursing boundary is blurred, insofar as the nurses are portrayed as prepared to challenge the doctor's clinical decision making, through its narrative structure the story simultaneously performs boundary-work.

This extract was produced in the interview context. I have included it because it illustrates the micropolitical work that nurses' atrocity stories are oriented to and the linguistic devices through which this work is achieved. Still, it does not capture the powerful ways in which atrocity stories constitute occupational boundaries when they are produced among the nursing group.

\section{Boundary-Work in Flight}

The next extract is taken from my fieldnotes and was recounted by the night staff to the day staff as they changed shifts. Here the tale of the incompetent doctor is embedded in a wider narrative about the unexpected death of a patient. This extract omits interactional detail that a tape recording would have captured. Moreover, it was particularly difficult to make detailed verbatim field notes of this piece of interaction, precisely because nurses produced the story collaboratively. Notwithstanding these considerations, however, the extract below is suggestive of how the production and receipt of stories in flight perform a dual boundary-work function in the workplace.

\section{Extract 2: Fieldnotes}

When I arrived the nurses were talking about a death that had occurred in the 1 night. Evidently they had been discussing it for some time. Debbie ((night 2 nurse)) was recounting the events leading to the patient's death. She explained 3 that when the night staff had taken the patient's blood pressure when they came on 4 ((duty)) it was very low - seventy over forty. She said that the doctor had put up 5 some Haemacell ((blood substitute)) and that she still wasn't happy and so they 6 gave him another one. Agnes ((night nurse)) said, "But he was Cheyne Stoking 7 ((pattern of respirations taken to signify the imminence of death], wasn't he?" 8 Debbie ((night nurse)) said, "Yes. The doctor was hopeless." I said to her, 'He's 9 Cheyne Stoking,' and she said, 'What's that? What are his respirations like?"' 10 There was generalized laughter all round. Debbie went on, "I said three 11 ((respirations)) a minute if you're lucky." Audrey ((night nurse)) chipped in 12 ((laughing)), "and that's being generous!" Debbie went on complaining that the 13 doctors wouldn't leave him "the patient" alone. "They called the crash team 14 ((resuscitation team)), but he was dead wasn't he?" Agnes said, "Yes. Oh yes." 15 Debbie said, "Why couldn't they leave him to die with a bit of dignity?" Mable 16 ((day nurse) ) said, "I don't think they assess these patients adequately before $\quad 17$ theater."

The night staff collaboratively produced the story in extract 2 . Agnes, Audrey and Debbie each makes a contribution to the narrative. This is a powerful device for accomplishing consensus and a shared orientation to a given state of affairs (Eder 
1988; Edwards 1997; Lerner 1992, 1995). It also reveals another way in which nurses' storytelling positions the doctor in the minority.

Debbie begins the tale by setting the scene: the nurses had discovered that the patient's blood pressure had become dangerously low, so they summoned the doctor who responded by giving a blood substitute (Haemacell). The doctor's competence is criticized by Agnes (7) when she makes the observation "but he was Cheyne Stoking." Cheyne Stoking refers to a pattern of respirations typically considered to signal death. Her comment thus carries implicit criticism. In giving the patient Haemacell, the doctor acted inappropriately: it was too late for active treatment of this kind. Debbie makes Agnes's appraisal explicit when she describes the doctor as "hopeless" and warrants this view by recounting an exchange that directly involved her (9-10).

The use of jargon in this extract is also interesting. Using specialized language implies a a claim to knowledge (Meehan 1981; Pilnick 1998). The nurse's use of the term "Cheyne Stoking" in this extract serves to establish her knowledge and to underscore the doctor's shortcomings. ${ }^{13}$

Understanding the meaning of stories depends on knowledge of a setting; storytellers must either assume knowledge or make the salient details of the narrative explicit. Stories thus have to be assembled with a particular audience in mind. The use of specialized terms (e.g., "Cheyne Stoking") in this extract illustrates the way in which the recipient design of nurses' stories does boundary-work by constituting the nursing group. Among members of a group, shared language helps to accomplish solidarity and establish a common sense of identity (Barnlund 1976, cited by Meehan 1981). The laughter at line 11 displays the story recipients' understanding of the significance of Debbie's utterances. By trading on their taken-for-granted knowledge in this way, the story displays nurses' superior competence vis-à-vis the doctor and, as the butt of their collective humor, casts the doctor as the outsider.

\section{Narrating Collective Experience}

Another way in which nurses' atrocity stories establish a boundary with medicine and constitute a common occupational identity is through their formulation of nurses' problems with doctors as a patterned part of the collective experience of the occupation. As we have seen, Dingwall (1977) makes this point in relation to his work on health visitors, and others have also shown how stories build solidarity and function to constitute occupational groups by underlining their shared experiences (e.g., Bosk 1979). Assertions of this kind feel intuitively right, but these analyses tend to end at this point, without attending to how stories and their telling accomplish this effect.

One way in which stories seem to accomplish this kind of discursive action is by moving between descriptions of a specific episode to observations of a more general pattern of behavior, as evident in the general criticism at the conclusion of the previous extract in which the claim is made that doctors do not assess patients adequately before theater (15). Similarly note the statement in extract 1: "Yeah he can 
be a bit funny sometimes" (39). In this case the generalization relates to the specific doctor in question rather than to the medical profession as a whole.

Storytellers also formulate specific instances as part of a pattern through their production in a series. As Ryave (1978) notes, stories are frequently told in clusters. When these stories are topically related, he refers to them as a "series of stories." Both Dingwall (1977) and Bosk (1979) observed this in the occupations they studied. They underline the competitive nature of storytelling on such occasions: each successive tale contains more drama or surprise than the preceding one. However, I suggest that nurses' production of multiple stories also works to portray their relationships with doctors as part of collective experience.

Extract 3 is taken from my field notes. It includes stories produced in a series by two staff nurses in the context of a discussion about the difficulties of getting doctors to come to the wards at night. The first relates to an incident in which a staff nurse, attending to an unwell patient, struggles to get assistance from either the doctor or the night Sister. The second, although topically relevant, carries an additional moral lesson: nurses should have more confidence in their own judgment. Like the other stories we have studied, both are rhetorically assembled to align the story recipient to the nursing perspective and isolate the doctor. Moreover, produced in a series, these stories work to constitute nurses' problems with doctors as part of a shared occupational perspective.

\section{Extract 3: Field Notes}

SN1: But they just don't organize their work very well. It would be better if they came round all the wards, but they don't. They all sit around on the admissions ward chatting. We can be here ages waiting for them to come and it might only be to put a cannula ((fine-bore tube that is inserted into the vein to allow the administration of fluids and medications)) in so a patient can have their IV ((intravenous)) antibiotics.

SN2: The other week I was on Primrose Ward and a man was having an MI ((heart attack)) and the doctor wouldn't answer his bleep and so I bleeped Sister Cumberledge and she wouldn't answer either. I'd done the ECG ((electrocardiogram) ) and there wasn't anything more I could do. I was just about to send Maud down to the CCU ((coronary care unit)) with the ECG when he came. But when you've done everything you can and you think, "Well all I can do now is watch him go off ((deteriorate) ) and then put the call out ((call the resuscitation team))."

SN1: I was on here one night and I bleeped the doctor because I was worried ward and would be up when he could. Well Jane said there were five of them down there all huddled together round the desk and just two patients. He didn't come and the man was getting worse. I bleeped him again and still he didn't come. So in the end I fast bleeped him. Now if I fast bleep him then he should come to the ward but he didn't-he phoned. I said that the patient was getting worse. He was gray and clammy and I was sure he was in acute LVF ((heart 
"Look if you don't come and see him he'll arrest" ((cardiac arrest)) and just as I 26 put down the phone he did. He died. I wish I'd given him the Frusemide now. $\quad 27$ He needn't have died-all he needed was some Diamorphine and some Frusemide. 28 I was mad-it was awful, just watching him literally gasping for breath.

This extract comprises a first and second story. It begins with SN1's complaint about nurses having to wait for doctors to come to the ward. Her portrayal is designed to attribute blame and responsibility (Mandelbaum 1993): doctors do not organize their work well, and they spend their time chatting. The first story (line 7), told by SN2, appears to be produced as a warrant for SN1's assertion. She recounts an incident in which a patient is having a heart attack (MI) and the nurse cannot summon the assistance of either the doctor or the night Sister. The nurse has exhausted all the options available to her and has resorted to sending a copy of the ECG to the coronary care unit, when the doctor finally arrives. The story concludes with a general statement of the sense of helplessness nurses experience when left to watch a patient's condition decline but are unable to intervene any further (lines 12-14).

The second story (15) is topically related, but the themes are dramatically developed: The story contains rich details and has a tragic outcome, and the account is designed to explicitly attribute blame and responsibility. Like story 1 , this tale is about the doctor who is bleeped but fails to come to the ward. Notice how Jane's observations that there were five doctors on the admissions unit attending to only two patients is designed to undermine the doctor's claim that he is busy. This detail of the talk (17-18) also resonates with her earlier assertion in lines 2 and 3 that doctors sit around chatting.

When the patient's condition deteriorates, the nurse bleeps the doctor again, but he does not respond, so she "fast bleeps" him. The storyteller outlines the "fast bleeps" procedure and uses this to underscore the shortcomings of the doctor, who does not act in accordance with organizational procedure: he telephones instead of coming to the ward. Including this detail also helps to underwrite the "point" of the story: the doctor prescribes medication (Frusemide) based on the information given him; the teller refuses to administer it. Notice how the nurses' account of her decision is oriented to a possible counterargument. She knows that she can accept "verbal orders," but this is not the issue; legally nurses cannot make medical diagnoses, and this is the (legitimate) basis for her action.

In contrast to extract 1, then, in which the medical-nursing boundary is blurred, this story is oriented to the limits of nursing jurisdiction. Regrettably the patient dies, and the teller reflects on the outcome: had she trusted her own judgment things may have turned out differently. She ends by echoing the conclusions of the first story. Ryave (1978) refers to this as a "same-significance procedure," that is, where a successive storyteller uses the same significance statement of the preceding storyteller to construct his or her recounting. Here, then, the production of two topically related stories serves to underwrite nurses' experiences with doctors as part of a pattern and as shared in common. Both also function as moral parables: nurses must have more confidence in their own abilities and should not be constrained by formal jurisdictional boundaries. 


\section{Supported Storytelling}

A striking feature of storytelling in a group situation is the extent to which the story recipients interactionally support it. As we have seen, the story recipients may themselves become storytellers. A high degree of consensus marked the production and receipt of nurses' stories about medical staff. Thus storytelling performs boundary-work by affirming the collective experience and shared perspective of the in-group (nurses) with respect to the out-group (doctors). The next extract reveals how senior nurses charged with implementing changes to the scope of nursing practice at the hospital linked stories of medical incompetence during their meeting. These stories emerged in the context of a discussion about developing a program to train nurses in defibrillation techniques. The question arose as to whether doctors would also benefit from the program.

Extract 4: Meeting-Tape recording

Dawn: The other thing which like I think Gary raised this point (.) 1 umm its quite a rigorous thing and umm (.) 2 should we be doing that for the doctors hehh as well? 3

((laughter))

(.) because they're not very good at it

Polly: (...)

Dawn: think they should have some equivalent

Gary: Hehh hehh

Polly: That's right cause they're going to feel [threatened $=\quad 9$

$\begin{array}{ll}\text { Gary: } & 10\end{array}$

Polly: =aren't they if we know m[ore than they do 11

$\begin{array}{lll}\text { Gary: } & {[(\ldots)} & 12\end{array}$

Dawn: I had a registrar ((grade of doctor below consultant)) the 13 $\begin{array}{ll}\text { other [day umm } & 14\end{array}$

Mrs. Brown: [yeah they want to be careful don't 15 $\begin{array}{ll}\text { they [we won't }= & 16\end{array}$

[ ]: [yeah yeah 17

Mrs. Brown: =need doctors soon 18

Dawn: yeah 19

[ ]: heh heh heh hahh 20

Gary: I've seen appalling practice from doctors (.) [which (.) which 21

[ ]: actually [yeah 22

Gary: puts the $\quad 24$

Mrs. Brown: (protocol) 25

Gary: puts the patient himself and (.) the nursing staff at risk 26

$\begin{array}{ll}\text { Dawn: [Yeah } & 27\end{array}$

June: [Yes I've seen doctors putting nursing [staff at risk $=\quad 28$

$\begin{array}{lll}\text { Gary: } & \text { [yeah } & 29\end{array}$

June: = they're messing about $=\quad 30$

Mrs Brown: Yeah 31

Gary: ummm $\quad 32$

June: = just sort of standing there with charged paddles in their 'ands $\quad 33$

$\begin{array}{ll}\text { saying "right }(.)= & 34\end{array}$ 


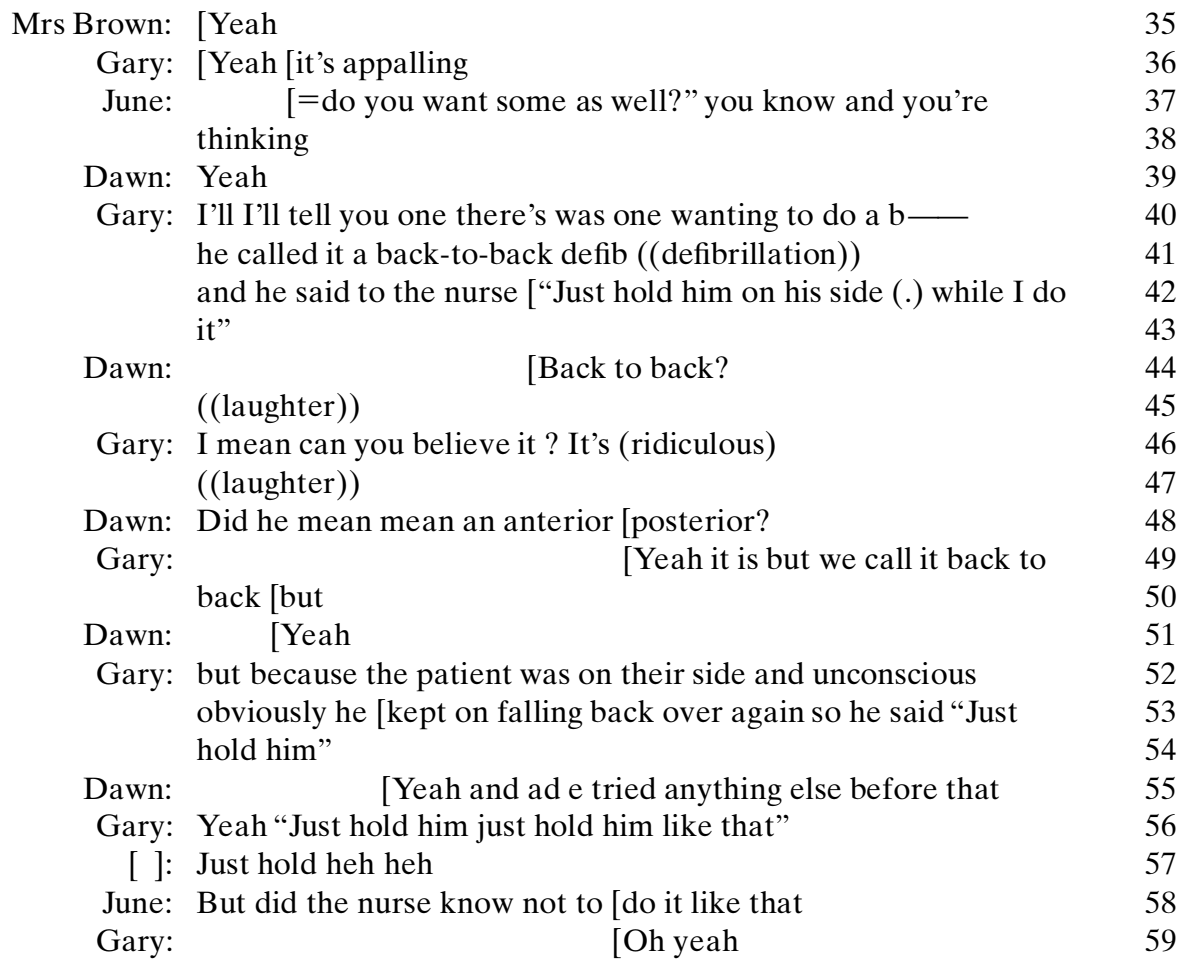

Nurses produced this series of stories during an explicit discussion of the possibility of role conflict between nursing and medicine. At line 13 Dawn appears to initiate a story, "I had a registrar the other day," which may have been an attempt to warrant her assertion that doctors lack defibrillation skills (4). Her observations stimulated animated exchanges among the other participants about the possibility of doctors being made redundant as nurses improve their skills.

Gary's utterance in lines 21,24, and 26 appears to be an attempt to produce a story preface (Sacks 1992) beginning with a statement of the tale's significance, that doctors' bad practice endangers nursing staff and patients. ${ }^{14}$ Gary fails to secure the conversational floor, however, and his talk seems to act as a trigger for the production of a topically relevant story by June (28): "Yes I've seen doctors putting nurses at risk." Notice how the story recipients support June's story with interjections and comments that underwrite its status as part of nurses' shared experience $(29,31,35$, $36,39)$. Gary immediately follows with a related story in which the doctor's actions are described as even more dangerous than those described by June.

This series of stories serves to underline doctors' technical shortcomings, and as such they support Dawn's assertion at lines 3 and 7 of their need for training. Doctors are portrayed as having a cavalier attitude to established procedures. In both cases, the precise nature of the "risks" caused by doctors' disregard for protocols remains unexplicated, again revealing the ways in which nurses' stories trade on shared knowledge for their rhetorical force. 
One feature of this extract that separates it from the others in my data is Dawn's request that Gary clarify the meaning of his utterance (48). Dawn is the resuscitation training officer and a new addition to the hospital staff. She does not possess the local interpretive resources to understand the moral force of the tale from the story's detail and has to ask for more information. This deviant case highlights how, by trading on taken-for-granted knowledge, nurses' stories work to constitute the local colleague group. Insiders "get" the moral point of the tale from the available information; outsiders do not.

I have argued that atrocity stories perform dual boundary-work functions in the workplace. I have suggested that the rhetorical form of nurses' stories serves to create a moral division of labor between medicine and nursing and that this discursive work is supported by the pattern of nurses' storytelling, which also simultaneously works to constitute membership in the colleague group. Analysis of their discursive detail and the way in which they are produced and received in flight reveals that atrocity stories achieve this interactional business in several ways: through the juxtaposition of the nursing and medical perspective, by aligning the story recipient with the nursing standpoint, and by formulating the nursing experience of doctors as part of a pattern and as shared in common.

\section{ATROCITY STORIES - A SHARED RHETORIC?}

I now want to shift the analytic focus away from individual stories to their place in nursing's occupational culture. A key theme in Gieryn's $(1983,1999)$ work is his insistence on science's nonessentialism. Science is no single thing: it is rhetorically transmogrified according to the purposes at hand. As we have seen, however, one of the striking features of ward nurses' stories about doctors is their consensual nature. Not only did nurses' stories about doctors accomplish a shared view on the occasions of their telling, nurses also drew on common interpretive resources through which they constituted the medical-nursing boundary in a particular way. Restrictions of space have only permitted the inclusion of a small representative selection in this article.

Through these stories nurses present themselves as possessing considerable expertise that doctors often do not recognize and in which they themselves ought to have greater confidence. The stories portray nurses as capable of assessing the clinical competence of their medical colleagues but rarely openly challenging their technical abilities. Indeed, I have only one story in my data in which a storyteller described a nurse as directly criticizing a doctor. This case relates to an experienced nurse with specialist expertise in defibrillation. So, although nurses' stories confirm their technical competence, they also display an orientation to the limits of their jurisdiction with respect to medicine. Indeed, in the second story in extract 3 , adherence to formal role boundaries results in the death of a patient.

At the same time, however, the recurring themes in these stories also work to constitute the value of nursing knowledge and the distinctive nursing contribution 
to health care. The stories represent doctors as poor communicators who lack empathy with the patient's perspective. This portrayal of doctors is contrasted with nurses' (superior) communication skills and their holistic knowledge of the patient derived from daily contact. There are clear parallels here with Anspach's (1987, 1993) findings. She observes that the social organization of hospital work positions doctors and nurses differently in relation to the patient. This creates different kinds of knowledge that can lead to ethical disagreements.

Whereas nurses' stories are oriented to the limits of their jurisdiction with respect to doctors' technical competence, they portray nurses as prepared to challenge medical decision making in relation to patient treatment decisions, as we saw in extract 1 . So while nurses' stories function to constitute a moral boundary between nursing and medicine, they may also transform the technical division of labor. Chambliss (1997) suggests that what appear to be ethical dilemmas between nurses and doctors are often thinly disguised turf battles. A number of the stories in this article described nurses challenging medicine in an advocacy role. Even the story in which the patient died because of the nurses' reluctance to make a diagnosis might serve as a future reminder of nurses' diagnostic skills.

In underlining both their technical expertise and the value of "care" in their stories, nurses appeared to be drawing on the rhetoric employed in the jurisdictional disputes that were taking place in the public sphere at the time. The nurse managers in the study site also told stories of a very similar kind. Somewhat ironically, the ideological debates over the nursing role appeared to have equipped the members of the occupation in the study site with a shared interpretive repertoire with which to constitute their occupational identity vis-à-vis the medical profession. These findings raise some interesting questions about the relationship between boundarywork processes in different domains.

A remarkable degree of consensus may have been evident among nurses at all levels of the organization about the medical-nursing boundary, but this was not the case with respect to the support-worker interface. Most of the stories about HCAs that I have in my data were recounted by senior nurses; these were managers who were removed from the daily reality of ward work. Ward nurses told comparatively few atrocity stories about support staff.

At one level these differences may reflect the limited opportunities on the wards for storytelling of this kind. Because nurses and support staff worked together, it was difficult for them to tell stories about each other. Indeed, all the ward nurses' stories were produced in the interview situation. At another level, however, ward nurses' tales centered on topics different from those recounted by nurse managers, revealing subtly different concerns about this category of worker. Whereas nurse managers assembled stories to illustrate the implications of HCAs' entry into the hospital workforce for the quality of patient care, the ward nurses focused on their day-to-day relations with support staff and their failure to respect their professional expertise. In addition, nurse managers' stories echoed the ideology of New Nursing by making unfavorable comparisons between the task-oriented and routinized ap- 
proach of HCAs and the individualistic and holistic approach of nurses. No such juxtaposition can be found in ward staff's stories. Indeed, as the following example reveals, they explicitly contested the senior nurses' version of their occupational reality. The extract is taken from a tape recording of an in-service training day. The clinical manager who ran the course told a story about the practice of HCAs to an audience of ward-based nursing staff.

Greta ((nurse manager)) recounted a story about the HCA who was being trained 1 and had been taught by another HCA on the ward how to put the thermometers 2 under the arms of all thirty-four patients.

Manager: I said “^so you don't w:ork in teams?”(.) 4 she says "^oh yeah we do" she says "but we just need to get all 5 the temps ((taking patients' temperature)) done (.) and the obs 6 $\begin{array}{ll}\text { ((recording temperature, pulse and respirations) }) \text { done at the same } & 7\end{array}$ time" (.) 8 $\uparrow$ I said "well what abo:ut individualized patient care (.) and 9 don't you think its a bit like treating patients like a production $\quad 10$ line [type thing?" 11

[ ]: [Mmm 12

Manager: “^well now you've put it that way: (.) yeah” 13

Ward Sister: don't you think don't you think you'll always get that though $\quad 14$ ann (.) 15

Manager: veah^I'm [sure you will 16

Ward Sister: [you'll al- no matter whether you're wanting primary 17 nursing, team nursing, whatever nursing ${ }^{15} \quad 18$

((inaudible background talk)) 19

Manager: but don't you think it's very worrying? 20

Ward Sister: well it is yeah it is but the thing is you're always gonna 21 to get that because (.) you know (.) that they think they're 22 $\begin{array}{ll}\text { helping each other } \uparrow \text { out } & 23\end{array}$

Manager: Yeah. Yeah. I mean none of the thought processes 24 latched onto patient safety whether the thermometer 25 bro:ke an[d all this sort of thing hehh= 26

[ ]: [hehh hahh hehh 27

Manager: =erm there were nothing like tha:t and that really does 28 $\begin{array}{ll}\text { concer:n me when here we are as a nursing profession } & 29\end{array}$ trying to move towards something which is (.) more $\quad 30$ patient invol::ved and yet (.) the backlash of that (.) 31 $\begin{array}{ll}\text { and maybe you could argue it was staffing } & 32\end{array}$ I don't know the ins and outs of that (.) 33 is setups like this HCA was describing to me $\quad 34$

Ward Sister: but even if you've got plenty of staff you'll probably still get $\quad 35$ that $\uparrow$ I still I still say that (.) because they think they're all 36 $\begin{array}{ll}\text { helping each other out. } & 37\end{array}$

Manager: Mmm 38

Ward Sister: You know "I'll do your temps and you do my so and so" (.) 39

Manager: mmm 40

Ward Sister: [and you're always going to get it. 41

Staff Nurse: [well I never heard of thirty-four patients 42

Ward Sister: $\uparrow \mathrm{Mmm}$ ? $\quad 43$ 
Staff Nurse: have a thermometer shoved under their arm (.) 44

[I've never known that done 45

[ ]: (I've never known thirty-four thermometers) on a $\uparrow$ ward hehh 46

((generalized laughter and overlapping talk)) $\quad 47$

Manager: It happens. $\quad 48$

$\begin{array}{ll}((\text { laughter })) & 49\end{array}$

[ ]: O::h my go:d $\quad 50$

[ ]: [...] if you got four! $\quad 51$

Staff Nurse: what's frightening is that nurses are giving their roles up (.) to 52

$\mathrm{HCAs}=$

[ ]: yeah [yeah yeah $\quad 54$

Staff Nurse: $\quad=$ [that's what's frightening about it really $\quad 55$

Manager: yeah ye[ah $\quad 56$

$\begin{array}{lll}\text { Staff Nurse: } & \text { [that's the bit that's a [(.) a worry for me } & 57\end{array}$

This extract is noteworthy for its lack of consensus. The nurse manager's story, in comparison to extract 4 , for example, receives no interactional support from the story recipients. Indeed, it is met with a succession of challenges that result in the manager reformulating the moral force of the tale in an attempt to secure agreement. The first challenge to the nurse manager's story is in line 14 with the claim by the ward Sister that HCAs always employed routinized methods because they tended to work together. Although the nurse manager expressed agreement with the ward Sister at line 16, she attempted to establish realignment with her own position with the question, "But don't you think its very worrying?" She was, however, only able to secure limited assent: the ward Sister's response at line 21 is mitigated by a reformulation of her initial objection.

Having failed to accomplish consensus, the nurse manager then shifts the significance aspect of the story to safety issues (24-25). This time her utterances are met with a measure of agreement with the laughter at line 27. Once she has accomplished alignment, the nurse manager returns to her initial formulation - that support workers' behavior is at odds with patient-centered models of care. Story recipients again contest her version of reality, first the ward Sister (35) who reiterates her position and then a staff nurse who implicitly questions the veridicality of the manager's story (42). The extract ends with the staff nurse introducing her own concerns about nurses giving up their roles to support staff, which is met with agreement from the group (54).

Although limitations of space do not permit a detailed examination of this extract, this example of a contested story stands in marked contrast to the consensual format that characterized the way in which nurses produced and received tales about doctors. While the public debates may have provided nurses with a shared language for constituting their boundary with medicine, that did not happen as far as HCAs were concerned.

\section{Intraoccupational Segmentation Processes?}

These findings indicate intraoccupational segmentation processes. As Bucher and Strauss (1961) have argued, a profession is not a homogeneous entity and may 
be more fruitfully considered as constituted by different segments. Sectors of the profession come into contact with different occupational and professional groups, and a sector might have quite special problems with other occupations that they do not share with other members in the profession. Indeed, whereas nurse managers in the study site were eager to clearly differentiate nurses and HCAs (Allen 2000, 2001), on the wards I found little sense of a clear boundary between them. In fact, nurses emphasized the ward team rather than formal occupational status. Thus these findings support Zerubavel's (1979) claim that the temporal-spatial organization of work can lead to work group solidarities that cut across conventional lines of demarcation.

\section{Friction and Occupational Control?}

At another level HCAs were permanent members of the ward staff, whereas junior doctors were transient players, with whom ward nurses did not have the same shared understandings. All of the atrocity stories about HCA support staff came from one ward where several support staff members were relatively new and with whom nurses had not yet developed trust. Moreover, a number of the stories related to a particular deviant HCA who had made herself unpopular with the nurses by refusing to undertake certain tasks even though she had the requisite skills. Given that atrocity stories may serve to manage social friction, it is also significant that nurses had greater control over HCAs than they did medical staff.

\section{Ideological Ambiguity?}

Finally, the absence of a shared linguistic register vis-à-vis the nursing-HCA interface may also reflect the strains and ambiguities within the occupation's public professional rhetoric. The nursing profession has formed its jurisdictional claims through the language of "care" to establish its professional autonomy vis-à-vis medicine. Yet as a number of authors have cautioned, inherent dangers are evident in this kind of gendered occupational strategy because of the systematic devaluation of the skills of women within dominant societal norms (e.g., Aldridge 1994). The association of care with women's domestic roles undermines nurses' claims that they require theoretical knowledge and practical training. Asserting a unique holistic approach to patient care is one way the nursing profession has sought to press its claims and to differentiate the nature of its contribution from that of lay carers. It was precisely this sort of contrast that the nurse manager was making in the last extract.

While undoubtedly an important professional aspiration, nurses cannot realize their ideal holistic model of care in their real world of practice where they deal with multiple patient assignments and institutions provide care with a mixture of qualified staff, HCAs, and students in training. Owing to the pressures of work on the ward, nurses had to trust HCAs to carry out their work competently with minimal supervision. Furthermore, many of the features of the so-called non-professional 
approach, such as routinization, which leaders of the nursing profession had attributed to HCAs in the public jurisdictional claims, also characterized their own practice. In short, the reality of nurses' everyday practice may well be too far removed from the professional rhetoric to provide a convincing vocabulary for ward nurses' storytelling. Yet to employ the alternative "service" position devalued the nursing contribution and contradicted the position of the nursing leadership.

\section{CONCLUSION}

I have considered the contribution of atrocity stories to the interactional accomplishment of nursing jurisdiction and have suggested that they may fruitfully be understood as a variant of boundary-work. Atrocity stories are an important interactional device through which bounded occupations are socially constituted in the workplace. I have argued that atrocity stories performed a dual boundary-work function - they constructed a boundary between nursing and other occupations while simultaneously constituting the nursing group-and I have explicated the ways in which they achieved this interactional business.

I have also argued that nurses' stories about doctors exhibited a high degree of consensus and appeared to employ a shared interpretive repertoire drawn from the boundary disputes in the public domain. This contrasted with the nurse-support boundary, which was constituted in divergent ways by different segments of the occupation in the stories they told. These findings indicate that researchers can extend Gieryn's $(1983,1999)$ work by considering the relationship between boundary-work processes in the workplace and the public sphere and by paying particular attention to intraoccupational segmentation processes.

One aim of this article is to address the lack of attention that earlier symbolic interactionist studies of the hospital division of labor have given to talk through attempting to strike a compromise between discourse and conversation analysis and more conventional ethnographic concerns. I believe that this approach has paid dividends. Not only has it indicated how the detailed analysis of storytelling in the workplace can assist us in developing our understanding of boundary-work processes, it has also suggested how we might develop a more sophisticated appreciation of the interrelationships of occupational groups and the lines of allegiance of intraoccupational segments. By attending to the stories that people tell about each other and how they produce and receive them, symbolic interactionists might learn more about a whole range of social groups.

Acknowledgments: I would like to thank the study participants for their support, on which the study depended. Alison Pilnick, Lesley Griffiths, Robert Dingwall, three anonymous reviewers for Symbolic Interaction, and Kathy Charmaz made helpful comments on various drafts of the manuscript. The Ph.D. research on which this article draws was supported by a United Kingdom Department of Health Nursing and Therapists Research Studentship. The dissertation was supervised by Rob- 
ert Dingwall (Social Studies) and Veronica James (Nursing and Midwifery Studies), University of Nottingham. A version of this article was presented at the Welsh Regional British Sociological Association Medical Sociology Group.

\section{NOTES}

1. This is true of much of the traditional ethnographic literature. Claims are made about the purposes stories serve without detailed analysis of how they actually accomplish the functions that are attributed to them.

2. This is also true of many of the functions attributed to atrocity stories in the traditional ethnographic literature.

3. The UKCC (United Kingdom Central Council for Nursing, Midwifery, and Health Visiting) is a statutory body responsible for the establishment of standards for training and professional conduct and the protection of the public from unsafe practice. It is charged with the responsibility for maintaining a single register of all practitioners and determining the conditions of entry. It is supported by four national boards of the four countries of the United KingdomEngland, Wales, Scotland and Northern Ireland - that have responsibility for implementing the policies and rules of the UKCC.

4. In the past nurses could undertake a two-year hospital-based training to become an enrolled nurse (EN) or a three-year course to become a registered nurse (RN). The EN/RN distinction in the United Kingdom has parallels with the LPN/RN distinction in the United States.

5. In the past nurses in training had always been an important source of labor on hospital wards.

6. Nursing auxiliaries in the United Kingdom are roughly equivalent to nursing aides in the United States.

7. Woodlands is a pseudonym.

8. A district general hospital is a nonteaching hospital that provides a range of services to a local population.

9. I am using the concept of negotiation in a fairly restrictive sense to refer to a direct interaction of some kind, either face-to-face or through technical or other means.

10. These figures do not add up because one person was interviewed more than once and two auxiliaries were interviewed together.

11. The named nurse is the nurse responsible for the patient's care. The concept of the named nurse was introduced in the United Kingdom in the context of the Patients Charter (one of a series of citizen's charters that set out standards the public could expect from service organizations) that stated that every patient was entitled to a named nurse. Although this was a government initiative, the original idea comes from a model of organizing the delivery of care known as primary nursing.

12. All stories have a punch line of some kind that points to the aspect of the event that makes it story-worthy.

13. I am grateful to Alison Pilnick for this observation.

14. Storytelling disrupts the turn-by-turn organization of talk and so needs to be announced (Jefferson 1978; Sacks 1978, 1992).

15. The Sister is referring to different methods of organizing nursing work. Primary nursing was held up by advocates of New Nursing as the ideal method of delivering patient-centered holistic care. The patients are assigned to a primary nurse who takes responsibility for planning and delivery of their care for the duration of that admission. When the primary nurse is unavailable, care is delivered by associate nurses. Team nursing is based on a differentiation of tasks among a stratified workforce. Care is provided to small groups of patients by a team of nurses.

\section{REFERENCES}

Abbott, Andrew. 1988. The System of Professions: An Essay on the Division of Expert Labour. Chicago: University of Chicago Press. 
Aldridge, Meryl. 1994. "Unlimited Liability? Emotional Labour in Nursing and Social Work." Journal of Advanced Nursing 20:722-28.

Allen, Davina. 1996. "The Shape of General Hospital Nursing: The Division of Labour at Work." Ph.D. dissertation, University of Nottingham.

1997. "The Nursing-Medical Boundary: A Negotiated Order?" Sociology of Health and Illness 19(4):498-520.

. 1998. "Doctor-Nurse Relationships: Accomplishing the Skill Mix in Health Care." Pp. 210-33 in The Sociology of the Caring Professions, 2d ed., edited by P. Abbott and L. Meerabeau. London:Taylor \& Francis.

. 2000. "Doing Occupational Demarcation: The 'Boundary-Work' of Nurse Managers in a District General Hospital.” Journal of Contemporary Ethnography 29(3):325-55.

.2001. The Changing Shape of Nursing Practice: The Role of Nurses in the Hospital Division of Labour. London: Routledge.

Allen, Davina and Patricia Lyne. 1997. "Nurses' Flexible Working Practices: Some Ethnographic Insights into Clinical Effectiveness." Clinical Effectiveness in Nursing 1(3):131 -40.

Anspach, Renee R. 1987. "Prognostic Conflict in Life-and-Death Decisions: The Organization as an Ecology of Knowledge." Journal of Health and Social Behaviour 28:215-31.

1993. Deciding Who Lives: Fateful Choices in the Intensive-Care Nursery. Berkeley: University of California Press.

Atkinson, J. Maxwell and Paul Drew. 1979. Order in Court. London and Atlantic Highlands, NJ: Macmillan and Humanities Press.

Atkinson, Paul. 1981. The Clinical Experience: The Construction and Reconstruction of Clinical Reality. Farnborough, Hants.: Gower.

. 1992. "The Ethnography of a Medical Setting: Reading, Writing, and Rhetoric." Qualitative Health Research 2(4):451-74.

1995. Medical Talk and Medical Work: The Liturgy of the Clinic. London: Sage.

Barnlund, Dean. 1976. "The Mystification of Meaning: Doctor-Patient Encounters." Journal of Medical Education 51:716-27.

Baruch, Geoffrey. 1981. "Moral Tales: Parents' Stories of Encounters with the Health Professions." Sociology of Health and Illness 3(3):275-95.

Bosk, Charles L. 1979. Forgive and Remember: Managing Medical Mistakes. Chicago: University of Chicago Press.

Brock, Stephen and Douglas A. Kleiber. 1994. "Narrative in Medicine: The Stories of Elite College Athletes' Career-ending Injuries." Qualitative Health Research 4(4):411 -30.

Bucher, Rue and Anselm Strauss. 1961. "Professions in Process." American Journal of Sociology 66(4):325 - 34.

Chambliss, Daniel. 1997. Beyond Caring: Hospitals, Nurses, and the Social Organization of Ethics. Chicago: University of Chicago Press.

Clark, Jack A. and Elliot G. Mishler. 1992. "Attending to Patients' Stories: Reframing the Clinical Task." Sociology of Health and Illness 14(3):344-72.

Davis, Kathy. 1988. Power under the Microscope. Dordrecht: Foris.

_ 1995. Reshaping the Female Body: The Dilemma of Cosmetic Surgery. London: Routledge.

Department of Health. 1989. Working for Patients: The Health Service Caring for the 1990s. London: HMSO.

Department of Health \& Social Security. 1983. Inquiry into NHS Management (The Griffiths Report). London:DHSS.

Department of Health \& Social Security. 1987. Hospital Medical Staffing (Achieving a Balance)— Plan for Action. Health Circular 87(25). London: HMSO.

Dingwall, Robert. 1977. "Atrocity Stories and Professional Relationships." Sociology of Work and Occupations 4:317-96.

Dingwall, Robert, Anne Marie Rafferty, and Charles Webster. 1988. An Introduction to the Social History of Nursing. London: Routledge.

Durkheim, Émile. 1933. The Division of Labour in Society. London: Collier-Macmillan. 
Eder, Donna. 1988. "Building Cohesion through Collaborative Narration." Social Psychology Quarterly 51:225-35.

Edwards, Derek. 1997. Discourse and Cognition. London:Sage.

Ehlich, Konrad, ed. 1980. Erzählen im Alltag. Frankfurt am Main: Suhrkamp.

Finlay, William, Elizabeth J. Mutran, Rodney R. Zeitler, and Christina S. Randall. 1990. "Queues and Care: How Medical Residents Organise Their Work in a Busy Clinic." Journal of Health and Social Behaviour 31:292-305.

Freidson, Eliot. 1976. "The Division of Labour as Social Interaction.” Social Problems 23:304-13.

General Medical Council. 1993. Tomorrow's Doctors. London: GMC.

Gieryn, Thomas. 1983. "Boundary-Work and the Demarcation of Science from Non-Science: Strains and Interests in Professional Ideologies of Scientists." American Sociological Review 48:781-95.

1999. Cultural Boundaries of Science: Credibility on the Line. Chicago: University of Chicago Press.

Griffiths, Lesley and David Hughes. 1994. “'Innocent Parties' and 'Disheartening' Experiences: Natural Rhetorics in Neuro-Rehabilitation Admissions Conferences." Qualitative Health Research 4(4):385-410.

Haas, Jack and William Shaffir. 1987. Becoming Doctors: The Adoption of the Cloak of Competence. London: JAI Press.

Hafferty, Frederick W. 1988. "Cadaver Stories and the Emotional Socialization of Medical Students." Journal of Health and Social Behaviour 29:344-56.

Hak, Tony. 1994. "The Interactional Form of Professional Dominance." Sociology of Health and Illness 16(4):469-88.

Hargreaves, Andrew. 1981. "Contrastive Rhetoric and Extremist Talk." Pp. 215-31 in Schools, Teachers and Teaching, edited by P. Woods. Milton Keynes, England: Open University Press.

Heritage, John. 1984. Garfinkel and Ethnomethodology. Oxford: Polity Press.

—_ 1990-1991. "Intention, Meaning and Strategy: Observations on Constraints on Interaction Analysis." Research on Language and Social Interaction, 24:311 -32.

Holstein, James. 1993. Court-ordered Insanity. Hawthorne, NY.: Aldine.

Hopper, Robert. 1990-1991. "Ethnography and Conversation Analysis after Talking Culture." Research on Language and Social Interaction, 24:161-72.

Hughes, David. 1982. "Control in the Medical Consultation: Organizing Talk in a Situation Where Co-Participants Have Differential Competence." Sociology 16:359-76.

-1988. "When Nurse Knows Best: Some Aspects of Nurse-Doctor Interaction in a Casualty Department." Sociology of Health and Illness 10:1-22.

Hughes, Everett C. [1971] 1984. The Sociological Eye. New Brunswick, NJ: Transaction Books.

Hunt, Scott A. and Robert D. Benford. 1994. "Identity Talk in the Peace and Justice Movement." Journal of Contemporary Ethnography, 22(4):488 -517.

Hunter, Kathryn M. 1991. Doctors' Stories: The Narrative Structure of Medical Knowledge. Princeton: Princeton University Press.

Jefferson, Gail. 1978. "Sequential Aspects of Storytelling in Conversation." Pp. 219-48 in Studies in the Organization of Conversational Interaction, edited by J. Schenkein. New York: Academic Press.

. 1984. "Caricature versus Detail: On Capturing the Particulars of Pronunciation in Transcripts of Conversational Data." Tilburg Papers on Language and Literature, No. 31. Tilburg, the Netherlands: University of Tilburg.

Klein, Rudolf. 1995. The New Politics of the NHS. 3d ed. London: Longman.

Kleinman, Arthur. 1988. The Illness Narratives: Suffering, Healing and the Human Condition. New York: Basic Books.

Larson, Magali S. 1977. The Rise of Professionalism: A Sociological Analysis. Berkeley: University of California Press.

Lerner, Gene. H. 1992. "Assisted Storytelling: Deploying Shared Knowledge as a Practical Matter." Qualitative Sociology 15(3):247-71. 
1995. "Turn Design and the Organization of Participation in Instructional Activities." Discourse Processes 19:111-31.

Mandelbaum, Jenny. 1993. "Assigning Responsibility in Conversational Storytelling: The Interactional Construction of Reality." Text 13(2):247-66.

Maynard, Douglas. 1989. "On the Ethnography and Analysis of Discourse in Institutional Settings." Pp. 127-46 in Perspectives on Social Problems, vol. 1, edited by J. Holstein and G. Miller, Greenwich, CT: JAI Press.

Meehan, Albert J. 1981. "Some Conversational Features of the Use of Medical Terms by Doctors and Patients." Pp.107-27 in Medical Work: Realities and Routines. Westmead: Gower.

Mellinger, Wayne Martin. 1994. "Negotiated Orders: The Negotiation of Directives in ParamedicNurse Interaction.” Symbolic Interaction 17:165-85.

Miller, Gale. 1997. "Towards Ethnographies of Institutional Discourse: Proposals and Suggestions. Pp. 155-71 in Context and Method in Qualitative Research, edited by G. Miller and R. Dingwall. London: Sage.

Moerman, Michael. 1988. Talking Culture: Ethnography and Conversation Analysis. Philadelphia: University of Philadelphia Press.

Moores, Yvonne. 1992. “Scope for Extensions.” Nursing Times 88(37):28 -29.

Myers, Loretta. 1979. The Socialization of Neophyte Nurses. Michigan: UMI Research Press.

National Health Service Management Executive. 1991. Junior Doctors: The New Deal. London: NHSME.

Nelson, Christian Kjaer. 1994. "Ethnomethodological Positions on the Use of Ethnographic Data in Conversation Analytic Research." Journal of Contemporary Ethnography 23:307-29.

Pilnick, Alison. 1998. "'Why Didn't You Just Say That?' Dealing with Issues of Asymmetry, Knowledge and Competence in the Pharmacist/Client Encounter." Sociology of Health and Illness 20(1):29-51.

Plummer, Ken. 1995. Telling Sexual Stories: Power, Change and Social Worlds. London: Routledge.

Rafferty, Anne Marie. 1992. "Nursing Policy and the Nationalization of Nursing: The Representation of 'Crisis' and the 'Crisis' of Representation" Pp. 68-83 in Policy Issues in Nursing, edited by J. Robinson, A. Gray and R. Elkan, Milton Keynes: Open University Press. 1996. The Politics of Nursing Knowledge. London: Routledge.

Ryave, Alan L. 1978. "On the Achievement of a Series of Stories.” Pp.113-32 in Studies in the Organization of Conversational Interaction, edited by J. Schenkein. New York: Academic Press.

Sacks, Harvey. 1978. "Some Technical Considerations of a Dirty Joke." Pp. 249-69 in Studies in the Organization of Conversational Interaction, edited by J. Schenkein. New York: Academic Press. .1992. Lectures on Conversation. 2 vols. Edited by G. Jefferson. 2 vols. Oxford: Blackwell.

Salvage, Jane. 1988. "Partnerships in Care? An Exploration of the Theory and Practice of the New Nursing in the UK." MS.c. dissertation, Royal Holloway and Bedford New College, University of London.

Shaw, Ian. 1993. "The Politics of Interprofessional Training - Lessons from Learning Disability." Journal of Interprofessional Care 7(3):255-62.

Snow, David A. and Leon Anderson. 1987. "Identity Work among the Homeless: The Verbal Construction and Avowal of Personal Identities." American Journal of Sociology. 92(6):133671.

Spencer, J. William. 1993. "Field Research on Human Service Encounters: Diverse Solutions to Common Problems." Sociological Methods and Research 21:327-93.

Stimson, Gerry and Beatrice Webb. 1975. Going to See the Doctor: The Consultation Process in General Practice. London: Routledge \& Kegan Paul.

Strauss, Anselm L., Shizuko Fagerhaugh, Barbara Suczek, and Carolyn Wiener. 1985. The Social Organization of Medical Work. Chicago: University of Chicago Press.

Strauss, Anselm L., Leonard Schatzman, Rue Bucher, Danuta Ehrlich, and Melvin Sabshin. 1963. "The Hospital and Its Negotiated Order." Pp. 147-69 in The Hospital in Modern Society, edited by E. Freidson. New York: Free Press of Glencoe. 
Turner, Bryan S. 1986. "The Vocabulary of Complaints: Nursing, Professionalism and Job Context." ANZJS 22(3):368 -87.

United Kingdom Central Council (UKCC). 1987. Project 2000: The Final Proposals. London: UKCC.

1992. The Scope of Professional Practice. London: UKCC.

Webb, Barbara and Gerry Stimson. 1976. "People's Accounts of Medical Encounters.” Pp. 108-22 in Studies in Everyday Medical Life, edited by M. Wadsworth and D. Robinson. London: Martin, Robertson.

West, Candace. 1996. "Ethnography and Orthography: A (Modest) Methodological Proposal." Journal of Contemporary Ethnography 25(3):327-52.

Williams, Gareth. 1984. "The Genesis of Chronic Illness: Narrative Re-Construction.” Sociology of Health and Illness 6:175-200.

Wright, Steve. 1995. "The Role of the Nurse: Extended or Expanded?" Nursing Standard 9(33):25-29.

Zerubavel, Eviatar. 1979. Patterns of Time in Hospital Life. Chicago: University of Chicago Press.

Zimmerman, Don H. 1998. "Identity, Context and Interaction." Pp. 87-106 in Identities in Talk, edited by C. Antaki and S. Widdicombe, London: Sage. 